Agricultural Journal 7 (5): 273-281, 2012

ISSN: $1816-9155$

(C) Medwell Journals, 2012

\title{
Assessment of Air Pollution Related Health Problems and Willingness to Pay for Improved Environment in Hanoi, Vietnam: An Application of Contingent Valuation Method
}

\author{
Nguyen Viet Hanh and Shin Hio Jung \\ Department of Agricultural and Resource Economics, Kangwon National University, \\ Chuncheon, 200-701 Gangwon-do, Republic of Korea
}

\begin{abstract}
The purpose of this study is to determine the disease factors that affect the willingness to pay for the environmental quality improvement and estimate the willingness to pay and treatment cost in Hanoi city using contingent valuation method. Binary logistic model and linear regression model are applied for the analysis. The results show that the diseases and treatment cost have powerful influences on WTP and WTP level. The truncate mean WTP value was 19749.7639 VND. WTP for each typical disease is also estimated. In particular, WTP of respiratory problem was highest with 24247.85301 VND while it was 25315.08039 VND for WTP of dermatitis the lowest being 11367.27651 VND for pneumonia.
\end{abstract}

Key words: Contingent valuation, air pollution, Willingness To Pay (WTP), disease, treatment cost, binary logistic model

\section{INTRODUCTION}

Environmental pollution is as an emerging problem in socioeconomic development process of developing countries. Apart from loss of beautiful scenery, it adversely affects ecological balance climate and human health. Ozone pollution can cause problems like respiratory and cardiovascular diseases, throat inflammation, chest pain and congestion. Water pollution causes approximately 14000 deaths day ${ }^{-1}$ in developing countries mostly due to contamination of drinking water by untreated sewage (http://answers.yahoo.com/ question/index?qid = 20110403112423AA qM720).

An estimated 700 million Indians have no access to proper toilet. About 1000 children die of diarrhea every day in India (http://www.andhranews.net/India/2008/ October/15-indian-children-die-diarrhoea.asp). Nearly 500 million Chinese lack access to safe drinking water. And 656,000 people die prematurely each year in China because of air pollution (http://targetstudy.com/ knowledge/day/75/world- pollution-prevention-day.html). With regard to health problems associated with environmental pollution, there have been a number of reports that show worsening impacts on human health. Oil spills cause skin irritations and rashes.

Noise pollution induces hearing loss, high blood pressure, stress and sleep disturbance. Mercury has been linked to developmental deficits and neurologic symptoms in children. Older people are mainly exposed to diseases induced by air pollution. Those with heart or lung disorders are under additional risk. Children and infants are also at serious risk. Lead and other heavy metals have been shown to cause neurological problems. Chemicals and radioactive substances can cause cancer as well as birth defects.

In addition to health problems environmental pollution poses serious economic impact. For instance the cost of air and water pollution in China is between 3.5 and $8 \%$ of the GDP in 1997 (World Bank, 2007). In 1950, following the construction of an acetaldehyde manufacturing company by chisso corporation in Minamata Japan, there have been serious fatalities due to the release of methyl mercury into food chain which resulted in the death of 107 workers and the poisoning of 793 victims. The total payment in compensation amounted $\$ 67.3$ million. Similarly, forest fire in Indonesia affected 70 million people resulting in respiratory diseases to $>40.000$ people in 1997. The total cost of this was estimated to be $\$ 220$ billion.

To reduce material damages as well as disease burden caused by environmental pollution, it is necessary to establish fund for purchase of technical materials and equipments, construct landfills and solid waste disposal, employ labor force, management and waste collection vehicles, sweeper, collector, public trash, etc. One of best ways to build this fund is based on community

Corresponding Author: Shin Hio Jung, Department of Agricultural and Resource Economics, Kangwon National University, Chuncheon, 200-701 Gangwon-do, Republic of Korea 
participation where everyone is using it as public good in addition to government's subsidy. Previous studies have used contingent valuation method to estimate willingness to pay for environmental protection fund. Zhongmin et al. (2003) measured the total economic value of restoring ecosystem services in Enjina region China. They used the CVM to obtain estimates of WTP for restoring Enjina ecosystem services. To capture the respondents' willingness to pay they used a Payment Card (PC) format and a 12 page survey booklet with maps depicting the reasons why Enjina ecosystem deteriorated.

In the $\mathrm{PC}$ format, respondents are confronted with an ordered sequence of bids where they choose the maximum amount that they are willing to pay. The result of this study shows that respondents would pay an average of $19.37 \mathrm{RMB}$ year ${ }^{-1}$ with 20.78 per household for the main river area and 16.41 per household for the rest of Hei basin. The aggregate benefit to residents of the Hei basin is 8.84 million annually for 20 years. Taking into account an environmental discount rate calculated by using respondents equivalent utility between periodical payments and lump sum payments, the present value of aggregate benefit of restoring enjina ecosystem was 55.33 million.

Arin and Kramer (2002) carried out an exploratory contingent valuation study on diver demand for visiting a marine sanctuary among foreign and local tourists in three major dive destinations in the Philippines. Using CVM, they found that a charge on entrance fee to visitors is one way to finance marine reserves. This is also a way for local communities to recover the rent of their resource in compensation. Revenues thus collected would help cover maintenance and anti-fishing rule enforcement costs of marine reserves. Furthermore, the entrance fee may be used as a tool to regulate the number of visitors to minimize diver damage. The maximum WTP was modeled as a function of age, gender, income, level of education, general interest in environmental protection, residence and type of diving (scuba and snorkel). Then, the maximum WTP of each diver was elicited through the contingent valuation question.

The results suggested that the average WTP is considerably higher on Mactan Island than in Anilao and Alona Beach where the average WTP was US\$3.7 in Anilao, US\$5.5 on Mactan and US\$3.4 on Alona Beach. Based on the survey results a positive willingness to pay to enter marine sanctuaries where fishing is one of the major threats to coral reefs is prohibited. Estimated annual potential revenues range from US\$0.85-1 million on Mactan Island, US\$95-116 thousand in Anilao and from US\$3.5-5.3 thousand on Alona beach. These revenues could be used to support coral reef conservation and possibly the creation of alternative employment opportunities for locals who would be barred from fishing.

In recent decades, Hanoi is facing serious environmental pollution problems as a consequence of socio-economic development process. Concentration of contaminants has surpassed acceptable levels. For instance, $\mathrm{PM}_{10}$ is 2-4 times higher than acceptable levels. On the other hand, the flow of untreated water that directly effluents into rivers, ponds and lakes is increasing around $510.000 \mathrm{~m}^{3}$ day $^{-1}$. Amonia concentration in lakes fluctuates from $0.58-51.5 \mathrm{mg} \mathrm{L} \mathrm{L}^{-1}$, meanwhile the concentration of $\mathrm{B}$ (Boron) in water is $25 \mathrm{mg} \mathrm{L}^{-1}$ which is well beyond the acceptable limit ranging between 13-68 mg L $\mathrm{m}^{-1}$ BOD (Biochemical Oxygen Demand). Concentration of BOD and COD (Chemical Oxygen Demand) levels in water in 2004 was much higher (7-10 times) than those in 1994. Since, researchers study the contingent valuation method and problem affected to health human risk in Hanoi Vietnam to find out causes of environmental pollution its impact to human health as well as estimate WTP for environmental quality improvement to help the environmental policy makers deploy and implement for environmental pollution reducing programs.

\section{MATERIALS AND METHODS}

Data collection: Data was collected from 400 residents living in five parts of Hanoi city namely; Hoan Kiem, Cau Giay, Thanh Xuan, Dong Da, Hoang Mai through a structured questionnaire. Of the total number of questionnaires distributed, 350 questionnaires were returned of which 10 questionnaires were rejected due to incomplete information. The questionnaire was divided into 4 sections. The 1 st part focused on individual characteristics like age, gender, occupation, education and income. The 2nd section included questions of individuals perceptions and assessments of air pollution problems. In the 3rd section researchers considered some typical common diseases that have strong connection with air pollution. Finally, the last section included questions about willingness to pay and willingness to pay levels by citizens for environmental improvement fund that will be used for reduction air pollution and improvement of environmental quality.

\section{Theoretical framework for environmental quality improvement}

The logistic model for analyzing DC responses: The logistic model is employed through WTP framework that is developed by Hanemann (1984) from which the Hicksian compensating and equivalent welfare measures 
may be obtained from Discrete Choice (DC) data (Bowker and Stoll, 1980). In this study, research attempt to obtain a measure of individual compensating surplus using discrete response data.

The contingent scenario and the DC valuation question present the individual with a given improvement in environmental quality at a stated price and then ask to cast a vote in favor of or against. The respondent takes the environmental quality as given but is free to decide on the value or the price to pay. The estimated WTP, therefore refers to a specific and fixed environmental improvement.

Additionally, researchers assume that beyond the factor of socioeconomic characteristics the increasing incidence of disease related to environment will have a strong impact on people's awareness of environmental quality and alter their behavior in protection and improvement of their own habitat. Since, researchers link WTP with some typical conventional diseases like dermatitis, trachoma, respiratory problems and pneumonia that are highly related with air pollution and their cost for treatment.

Suppose that an individual $\mathrm{j}$ in Hanoi city is presented with the possibility of obtaining a change in the quality of an environmental good $\mathrm{q}$ from $\mathrm{q}_{0}$ (the base case) to $q_{1}$ (improved environment) where $q_{1}$ is a preferred state to $q_{0}$, i.e., $q_{1}>q_{0}$. The indirect utility function of the jth individual for the base case can be expressed as (Hanemann, 1984; Amirnejad et al., 2006):

Where:

$$
V_{j}=\left(q_{0}, Y_{j}, Z_{j}, D_{j}, T_{j}, \varepsilon_{0 j}\right)
$$

$\mathrm{Y}=$ The income

$\mathrm{Z} \quad=$ The vector of characteristics of the individual

$\mathrm{D}=$ The vector of diseases related to air pollution and their treatment cost

$\mathrm{T}=$ The individual's assessment of the environmental quality

$\varepsilon=$ The stochastic component known to the individual respondent influenced by his/her taste and preferences but unobservable to the researcher

$\varepsilon_{0}, \varepsilon_{1}=$ Identically independently distributed random variables with zero means (Aminejad et al., 2006)

The subscript of $\varepsilon$ indicates status quo if it is zero and the alternative state if it is 1 . In Eq. 2, the subscript $j$ identifying the indirect utility function with the $j$ th individual is omitted from the function to avoid clutter but will be brought in whenever it is convenient to do so:

$$
\mathrm{V}\left(\mathrm{q}_{0}, \mathrm{Y}, \mathrm{Z}, \mathrm{D}, \mathrm{T}, \varepsilon_{0}\right)
$$

Since, the environmental quality improvement of Hanoi city is assumed to be viewed by the individual as an improvement the indirect utility function associated with this improvement may be expressed as (Hanemann, 1984; Amirnejad et al., 2006):

$$
\begin{gathered}
\mathrm{V}\left(\mathrm{q}_{1}, \mathrm{Y}, \mathrm{Z}, \mathrm{D}, \mathrm{T}, \boldsymbol{\varepsilon}_{1}\right) \\
\mathrm{V}_{\mathrm{j}}\left(\mathrm{q}_{1}, \mathrm{Y}, \mathrm{Z}, \mathrm{D}, \mathrm{T}, \boldsymbol{\varepsilon}_{1}\right) \geq \mathrm{V}_{\mathrm{j}}\left(\mathrm{q}_{0}, \mathrm{Y}, \mathrm{Z}, \mathrm{D}, \mathrm{T}, \boldsymbol{\varepsilon}_{0}\right)
\end{gathered}
$$

This means that the indirect utility associated with the environmental quality improvement is greater than or equal to the base case. Assuming that the individual is rational and maximizes utility (the rational agent assumption), the environmental quality improvement is preferred to the base case and its selection maximizes individual utility. However if the environmental quality improvement program is implemented and needs to get a fee with the bid amount (C) then the indirect utility associated with the improvement in Hanoi city becomes:

$$
\mathrm{V}\left(\mathrm{q}_{1}, \mathrm{Y}-\mathrm{C}, \mathrm{Z}, \mathrm{D}, \mathrm{T}, \boldsymbol{\varepsilon}_{1}\right)
$$

If researchers offer a Cost (C) to the individual for the environmental quality improvement then he/she will compare $\mathrm{V}\left(\mathrm{q}_{1}, \mathrm{Y}-\mathrm{C}, \mathrm{Z}, \mathrm{D}, \mathrm{T}, \boldsymbol{\varepsilon}_{1}\right)$ with $\mathrm{V}\left(\mathrm{q}_{0}, \mathrm{Y}, \mathrm{Z}, \boldsymbol{\varepsilon}_{0}\right)$ and respond yes only if $\mathrm{V}\left(\mathrm{q}_{1}, \mathrm{Y}-\mathrm{C}, \mathrm{Z}, \mathrm{D}, \mathrm{T}, \varepsilon_{1}\right) \geq \mathrm{V}\left(\mathrm{q}_{0}, \mathrm{Y}, \mathrm{Z}\right.$, $\varepsilon_{0}$ ) and no otherwise assuming that the individual is a utility function is able to formulate value from a given set of information and will reveal their true preferences when presented with a choice (Metchell and Carson, 1980). Then, the condition for voting yes can be expressed as (Haab and McConnell, 2000; Amirnejad et al., 2006):

$$
\mathrm{V}\left(\mathrm{q}_{1}, \mathrm{Y}-\mathrm{C}, \mathrm{Z}, \mathrm{D}, \mathrm{T}, \boldsymbol{\varepsilon}_{1}\right) \geq \mathrm{V}\left(\mathrm{q}_{0}, \mathrm{Y}, \mathrm{Z}, \mathrm{D}, \mathrm{T}, \boldsymbol{\varepsilon}_{0}\right)
$$

To measure the compensating surplus researchers ask the question: How much do you pay for the environmental quality improvement? The answer to this question provides a value for the compensating surplus. The necessary condition for equality between Eq. 1 and 3 is:

$$
\begin{aligned}
\Delta V\left(C, q_{1}, q_{0}, Y, Z, D, T, \varepsilon\right) & =V\left(q_{1}, Y-C, Z, D, T, \varepsilon_{1}\right) \\
& -V\left(q_{0}, Y, Z, D, T, \varepsilon_{0}\right)=0
\end{aligned}
$$

Where $\Delta \mathrm{V}$ represents utility difference. Equation 7 implies that the utility difference between the base case and the improvement after taking away $(\mathrm{C})$ equal 0 for the individual. Therefore, $\mathrm{C}=\mathrm{C}\left(\mathrm{q}_{1}, \mathrm{q}_{0}, \mathrm{Y}, \mathrm{Z}, \mathrm{D}, \mathrm{T}, \boldsymbol{\varepsilon}\right)$ is the maximum WTP for environmental change from $\mathrm{q}_{0}-\mathrm{q}_{1}$. Both 
$\mathrm{C}$ and $\Delta \mathrm{V}$ are stochastic and random variables in the utility functions such that the response yes or no can only be probabilistic ones (Hanemann, 1984). The probability of a yes response is the probability that the respondent thinks that he/she is better off in the proposed scenario. This conditional probability may be represented as:

$$
\operatorname{Pr}(\text { Yes } \mid \mathrm{X})=\operatorname{Pr}\left[\mathrm{V}\left(\mathrm{q}_{1}, \mathrm{Y}-\mathrm{C}, \mathrm{Z}, \mathrm{D}, \mathrm{T}, \varepsilon_{1}\right) \geq \mathrm{V}\left(\mathrm{q}_{0}, \mathrm{Y}, \mathrm{Z}, \mathrm{D}, \mathrm{T}, \varepsilon_{0}\right)\right]
$$

$\mathrm{X}$ is a vector of explanatory variables. Although, Eq. 8 may be used as a starting point for non-parametric estimation it is too general for parametric estimation (Haab and McConnell, 2000). To derive a suitable functional form Eq. 1 and 3 are restated by specifying utility as separable into two components deterministic and stochastic components which are additive as indicated as (Haab and McConnell, 2000):

$$
\begin{aligned}
& V\left(q_{0}, Y, Z, D, T, \varepsilon_{0}\right)=V\left(q_{0}, Y, Z, D, T\right)+\varepsilon_{0} \\
& V\left(q_{0}, Y, Z, D, T, \varepsilon_{0}\right)=V\left(q_{0}, Y, Z, D, T\right)+\varepsilon_{0}
\end{aligned}
$$

The contingent valuation scenario is designed to capture the deterministic element of the utility function (Haab and McConnell, 2000) which has as its arguments $\mathrm{q}_{1}, \mathrm{q}_{0}, \mathrm{Y}, \mathrm{A}, \mathrm{Z}, \mathrm{D}$. Equation 8 may now be restated as:

$\operatorname{Pr}(\mathrm{Yes} \mid \mathrm{X})=\operatorname{Pr}\left[\mathrm{V}\left(\mathrm{q}_{1}, \mathrm{Y}-\mathrm{C}, \mathrm{Z}, \mathrm{D}, \mathrm{T}\right)+\varepsilon_{1} \geq \mathrm{V}\left(\mathrm{q}_{0}, \mathrm{Y}, \mathrm{Z}, \mathrm{D}, \mathrm{T}\right)+\varepsilon_{0}\right]$

The right hand side of Eq. 11 may be rewritten after subtracting $\varepsilon_{0}$ from both sides of the inequality sign as:

$$
\operatorname{Pr}(\text { Yes } \mid X)=\operatorname{Pr}\left[\mathrm{V}\left(\mathrm{q}_{1}, \mathrm{Y}-\mathrm{C}, \mathrm{Z}, \mathrm{D}, \mathrm{T}\right)+\varepsilon_{1}-\varepsilon_{0} \geq \mathrm{V}\left(\mathrm{q}_{0}, \mathrm{Y}, \mathrm{Z}, \mathrm{D}, \mathrm{T}\right)\right]
$$

Let $\boldsymbol{\varepsilon}=\boldsymbol{\varepsilon}_{1}-\boldsymbol{\varepsilon}_{0}$. Then Eq.11 becomes:

$$
\operatorname{Pr}(\text { Yes } \mid X)=\operatorname{Pr}\left[V\left(q_{1}, Y-C, Z, D, T\right)+\varepsilon \geq V\left(q_{0}, Y, Z, D, T\right)\right]
$$

The right hand side of Eq. 13 may be rearranged in terms of the deterministic and stochastic components of indirect utility as:

$$
\operatorname{Pr}(\operatorname{Yes} \mid \mathrm{X})=\operatorname{Pr}\left[\begin{array}{l}
\mathrm{V}\left(\mathrm{q}_{1}, \mathrm{Y}-\mathrm{C}, \mathrm{Z}, \mathrm{D}, \mathrm{T}\right)- \\
\mathrm{V}\left(\mathrm{q}_{0}, \mathrm{Y}, \mathrm{Z}, \mathrm{D}, \mathrm{T}\right)+\varepsilon \geq 0
\end{array}\right]
$$

Haab and McConnell (2000) present a similar equation shown as:

$$
\operatorname{Pr}(\text { Yes } \mid X)=1-F_{\varepsilon}\left[V\left(q_{1}, Y-C, Z, D, T\right)+\varepsilon \geq V\left(q_{0}, Y, Z, D, T\right)\right]
$$

Where $F_{\varepsilon}($.$) is the cumulative distribution function of$ a standard $\operatorname{logistic}$ variant $\varepsilon$. The utility range of the environmental quality improvement may be expressed as:

$$
\Delta V=V\left(q_{1}, Y-C, Z, D, T\right)-V\left(q_{0}, Y, Z, D, T\right)+\varepsilon
$$

The parameterization of probability function may be achieved by expressing $\operatorname{Pr}($ Yes $\mid \mathrm{X})$ as a logit model as follows (assuming a linear utility function: $\Delta \mathrm{V}=\alpha$ $\beta \mathrm{C}+\gamma \mathrm{Y}+\lambda \mathrm{Z}+\mu \mathrm{D}+\omega \mathrm{T}$ :

$$
\begin{aligned}
\operatorname{Pr}(\text { Yes } \mid X) & =\frac{1}{1+\exp (-\Delta V)} \\
& =\frac{1}{1+\exp \{-(\alpha-\beta C+\gamma \mathrm{Y}+\lambda Z+\mu \mathrm{D}+\omega \mathrm{T})\}}
\end{aligned}
$$

Where:

$F_{\varepsilon}()=$. The cumulative distribution function (cdf) of a standard logistic variant $\varepsilon$ in the case of a logit model or the cdf of a standard normal variant in the case of a Probit Model (Hanamann, 1984; Lee and Han, 2002)

$\alpha=$ The intercept

$\beta=$ The coefficient of bid amount

$\gamma=$ The coefficient of income

$\lambda=$ The vector of coefficients of the socioeconomic and site characteristics

$\mu=$ The vector of disease factors

Equation 17 may be rewritten as:

$$
\{-(\alpha-\beta C+\gamma \mathrm{Y}+\lambda Z+\mu \mathrm{D}+\omega \mathrm{T})\}
$$

The parameters for the binary response model will be estimated using Maximum Likelihood (ML) since Generalized Least Squares (GLS) is ideal where many individuals are receiving the same bid offer or have the same income or have identical socioeconomic characteristics (Amirnejad et al., 2006). The odds in favor of a yes response can be expressed:

$$
\operatorname{Odds}(\text { Yes })=\operatorname{Pr}(\text { Yes } \mid \mathrm{X}) /[1-\operatorname{Pr}(\text { Yes } \mid \mathrm{X})]
$$

The ratio of $\operatorname{Pr}($ Yes $\mathrm{X})$ to the $\operatorname{Pr}(1-\operatorname{Pr}(\mathrm{Yes} \mathrm{X}))$ is the odds in favor of saying yes to the probability that it will say No to given bid amount $(\$ C)$. $P_{1}$ can be expressed as: 


$$
\begin{aligned}
& P_{1}=\frac{\operatorname{Pr}(\text { yes } \mid X)}{\operatorname{Pr}(1-\operatorname{Pr}(\text { yes } \mid X))} \\
& =\frac{[1+\exp \{-(\alpha \beta C+\gamma Y+\lambda Z+\mu D+\omega T)\}]^{-1}}{1-[1+\exp \{-(\alpha \beta C+\gamma \mathrm{Y}+\lambda Z+\mu \mathrm{D}+\omega \mathrm{T})\}]^{-1}} \\
& =\exp (\alpha \beta C+\gamma \mathrm{Y}+\lambda Z+\mu \mathrm{D}+\omega \mathrm{T})=\exp \left(\Delta \mathrm{V}_{\mathrm{i}}\right)
\end{aligned}
$$

Taking the natural log on both sides and disregarding the subscript i give us:

Where:

$$
\begin{aligned}
& \operatorname{In}(\text { odds })=\operatorname{In}[\exp (\Delta \mathrm{V})] \\
& \operatorname{In}(\mathrm{p})=\operatorname{In}[\exp (\Delta \mathrm{V})] \\
& \mathrm{L}=\operatorname{In}(\mathrm{p})=\operatorname{In}[\exp (\Delta \mathrm{V})] \\
& \mathrm{L}=\Delta \mathrm{V}=\alpha-\beta \mathrm{C}+\gamma \mathrm{Y}+\lambda \mathrm{Z}+\mu \mathrm{D}+\omega \mathrm{T}
\end{aligned}
$$

$\mathrm{L}=$ The logistic the log of the odds

$\alpha=$ The intercept and represents the value of the $\log$ odds in favor of saying yes if the suggested bid is zero (natural or threshold response rate)

$\beta=$ The coefficient of the bid amount

$\gamma=$ The coefficient of income

$\lambda=$ The vector of coefficients of $Z$

$\omega=$ The vector of coefficients of $\mathrm{T}(\alpha, \beta, \gamma, \lambda$ and $\omega$ measure the change in $\mathrm{L}$ for a unit change in the relevant variable)

In order to estimate the parameters of the logistic model, an error term $\mathrm{u}$ is added to Eq. 20, since $\mathrm{L}$ is not deterministic so that the equation becomes:

$$
\mathrm{L}=\Delta \mathrm{V}=\alpha-\beta \mathrm{C}+\gamma \mathrm{Y}+\lambda \mathrm{Z}+\mu \mathrm{D}+\omega \mathrm{T}+\mathrm{u}
$$

The estimated logit model provides parameter estimates in Eq. 21. The expected value of WTP (truncate mean) can be calculated by numerical integration of Eq. 22 ranging from zero to the maximum bid $(\$ \mathrm{C})$ as follows (Hanemann, 1984; Lee and Han, 2002; Haab and McConnell, 2000; Amirnejad et al., 2006):

$$
E(W T P)=\int_{0}^{\operatorname{MarC}} F_{n}(\Delta V) d(C)=\int_{0}^{\operatorname{MaxC}} \frac{1}{1+\exp \left\{-\left(\alpha^{*}+\beta C\right)\right\}} d(C)
$$

Where:

$$
\alpha^{*}=\alpha+\beta \overline{\mathrm{Y}}+\lambda \overline{\mathrm{Z}}+\mu \overline{\mathrm{D}}+\omega \overline{\mathrm{T}}
$$

Model for analyzing responses to the open-ended valuation questions: Open ended valuation questions produce a set of welfare measures $\operatorname{WTP}_{\mathrm{i}}(\mathrm{i}=1, \ldots, \mathrm{j}, \ldots, \mathrm{n})$ for $\mathrm{n}$ respondents in the sample. The mean WTP can be estimated as:
MeanWTP $=\frac{\sum_{\mathrm{i}}^{\mathrm{n}} \mathrm{WTP}_{\mathrm{i}}}{\mathrm{n}}$

An estimate of total value is obtained by multiplying the mean WTP by the population size. Alternatively, the total value may be calculated from the estimated WTP function (bid function) by using the population data on the estimated equation:

$$
\mathrm{WTP}=\mathrm{f}(\mathrm{I}, \mathrm{C}, \mathrm{IC}, \mathrm{A}, \mathrm{D})=\varepsilon+\alpha \mathrm{I}+\beta \mathrm{C}+\lambda \mathrm{IC}+\mu \mathrm{A}+\omega \mathrm{D}
$$

Where:

$\mathrm{WTP}=$ The Hicksian compensating measure of WTP

I $=$ The income of individual

$\mathrm{C}=$ The cost for treatment of individual

IC = The vector of socioeconomic characteristics of the individual including gender, age in years, education (defined as 1 for primary school, 2 for secondary school, 3 for high school, 4 for university and 5 for over university) and occupation (where 1 is for working and 0 for the unemployed individuals)

A $\quad$ The vector of individuals' assessments of air pollution and pollutant discharge sources that are linked with individual's observation and experience of environmental quality

$\mathrm{D}=$ The vector of conventional diseases as dermatitis, trachoma, respiratory and pneumonia

\section{RESULTS AND DISCUSSION}

\section{Descriptive statistics}

Environmental pollution problems and polluted source: The data gathered through questionnaire is useful as a source of information to assess the environmental quality and identify sources of pollutants in study area as accurately as possible. However, the degree of accuracy depends on the quality of the design of the questionnaire and the cognitive ability of the respondents. Perception varies among individuals in the community based on their profession educational background, etc. For instance, people working in environmental fields recognize and evaluate the environmental quality and the types of pollutants more accurately than those who work in other fields.

Respondents were asked about the severity of environmental pollution in order from 1-3 for environmental pollution state via three pollutant problems namely; water, air and solid waste and from 1-5 for five discharged pollutant sources as transport, industry, medicine, trade village and construction. 
Table 1 and 2 show the frequency analysis of the data. Accordingly, 209 (61.5\%) respondents have indicated that water pollution in Hanoi is the most serious problem; followed by air pollution with $109(32 \%)$ respondents and solid waste pollution with $22(6.5 \%)$ respondents.

With regard to pollutant discharge sources 120 (35.3\%) of respondents think that transport is the main reason that contributes to current pollution as shown in Table 2 . In recent years, the number of vehicle is rapidly increasing. According to Hanois Statistic Office, the total number of vehicle is $>4$ billion automobiles and motorbikes of which 368.325 are automobiles and about 3.8 billion are motorbikes in 2011. In addition, Hanoi has about 50 million vehicles that irregularly circulate. This huge number of vehicles will definitely result in a large emission of $\mathrm{CO}_{2}, \mathrm{NO}_{\mathrm{X}}, \mathrm{SO}$ and discharges into the environment. As shown in Table 3, the extent of emission is 301.779 ton year ${ }^{-1}$ for $\mathrm{CO}_{2}, 92.728$ ton year ${ }^{-1}$ of $\mathrm{NO}_{2}$, 18.928 ton year $^{-1}$ of $\mathrm{SO}_{2}$ and 47.462 ton year $^{-1}$ of VOCs.

With growing construction in Hanoi, there has been an increasing trend in the size and number of service industries putting much pressure on the environment. Pollutants are also released into the air as a result of the increasing manufacturing processes for commercial products where industrial smoke penetrates into atmosphere allowing chemicals to escape and industrial waste water diffuses wider into the land. As shown in Table 3, the emission from industries is 54.004 ton year ${ }^{-1}$ for $\mathrm{CO}_{2}, 151.031$ ton year ${ }^{-1}$ of $\mathrm{NO}_{2}, 272.497$ ton year ${ }^{-1}$ for $\mathrm{SO}_{2}, 854.000$ ton year ${ }^{-1}$ for VOCs. About $141(41.5 \%)$ of the sampled respondents consider this as second main source environmental pollution in Hanoi.

Along with the expanding construction activities in Hanoi, substances like PMx are produced and released into the atmosphere. As there is no strict control and enforcement of air pollution regulations there are growing threats from these potentially dangerous substances which causes air pollution as a main agent for typical diseases like pneumonia, respiratory etc. According to the

Table 1: Individuals assessment of environmental pollution level

\begin{tabular}{llll}
\hline Severity level & \multicolumn{1}{c}{1} & \multicolumn{1}{c}{2} & \multicolumn{1}{c}{3} \\
\hline Water & $209(61.5 \%)$ & $104(30.6 \%)$ & $27(7.9 \%)$ \\
Air & $109(32 \%)$ & $204(60 \%)$ & $27(8 \%)$ \\
Solid waste & $22(6.5 \%)$ & $33(9.7 \%)$ & $285(83.8 \%)$ \\
\hline
\end{tabular}

Bureau of Environmental Protection of Hanoi, concentrations of $\mathrm{PM}_{10}$ exceed 1.5-3 times that of the permitted standard at residential areas and 20-30 times in areas near construction sites. Furthermore, when vehicles move from the construction site to other regions they bring $\mathrm{PM}_{\mathrm{r}}$ and other pollutants in neighboring areas. This was reported as a third cause of environmental pollution by $50(14.7 \%)$ respondents (Table 2 ).

Environmental pollution related health problems: There is a 2 way interaction between environment and population where people's activities affect the environment they live in and the environment in turn impacts on people's lives. Living in good environment reduces the potential risk of environment related problems and diseases. On the other hand, living in a polluted environment increases the potential risk to health.

In recent years, Hanoi is facing serious environmental pollution caused as a part of its socioeconomic development process. Consequently, environmental problems like loss of ecological balance resource depletion and health problems are increasing. As shown in Table 4 and 5 , the incidence of respiratory diseases is reportedly highest with 212 (63.4\%)respondents followed by pneumonia with 153 (45\%) respondents and dermatitis and trachoma with 147 $(43.2 \%)$ respondents. However, pneumonia and dermatitis did not have any correlation with age of respondents while the incidence of respiratory problems and trachoma were found to be correlated with age of respondents with correlation coefficients of 0.20 and 0.12 , respectively at 1 and $5 \%$ levels of significance. During the survey, researchers have only interviewed respondents who were born and raised in Hanoi city. This means that the people who are older have better exposure and experience with the environment in Hanoi compared to younger ones. This confirms that the environmental pollution such as one of the main causes that is adversely impacting on Hanoi's residents.

Willingness to pay for improvement in environmental quality: The questionnaire on willingness to pay included 2 questions. The 1st question asked whether the respondent is willing to pay for an improvement in environmental quality. In the 2nd question, respondents were asked how much they will be willing to pay if the

Table 2: Individuals assessment of polluted sources

\begin{tabular}{lllll}
\hline Source/severity & \multicolumn{1}{c}{1} & \multicolumn{1}{c}{2} & \multicolumn{1}{c}{3} & \multicolumn{1}{c}{5} \\
Transport & $120(35.3 \%)$ & $114(33.5 \%)$ & $32(9.4 \%)$ & $42(12.35 \%)$ \\
Industry, service, life & $141(41.5 \%)$ & $74(21.8 \%)$ & $81(23.8 \%)$ & $32(9.4 \%)$ \\
Medicine & $27(7.9 \%)$ & $53(15.6 \%)$ & $113(33.2 \%)$ & $13(3.8 \%)$ \\
Trade village & $18(5.3 \%)$ & $39(11.5 \%)$ & $69(20.3 \%)$ & $88(25.9 \%)$ \\
Construction & $50(14.7 \%)$ & $59(14.4 \%)$ & $31(9.1 \%)$ & $94(27.6 \%)$ \\
\hline
\end{tabular}


Agric. J., 7 (5): 273-281, 2012

Table 3: Amount of pollutants is released by main source in 2006, unit: ton years $^{-1}$

\begin{tabular}{lcccc}
\hline Discharged source & $\mathrm{CO}_{2}$ & $\mathrm{NO}_{2}$ & $\mathrm{SO}_{2}$ & VOCs \\
\hline $\begin{array}{l}\text { Source by industry, } \\
\text { service, life }\end{array}$ & 54.004 & 151.031 & 272.497 & 854 \\
Transport & 301.779 & 92.728 & 18.928 & 47.462 \\
\hline
\end{tabular}

Bureau of Environmental Protection in 2006

Table 4: The incidence of respondent

\begin{tabular}{lll}
\hline Respondents & \multicolumn{1}{c}{ Yes } & No \\
\hline Dermatitis & $147(43.2 \%)$ & $193(56.2 \%)$ \\
Heart failure & $16(4.7 \%)$ & $324(95.3 \%)$ \\
Pneumonia & $153(45 \%)$ & $187(55 \%)$ \\
Respiratory & $212(63.4 \%)$ & $128(37.6 \%)$ \\
Trachoma & $147(43.2 \%)$ & $193(56.8 \%)$ \\
\hline
\end{tabular}

Table 5: Correlations between age and disease

Methods Dermatitis Pneumonia Respiratory Trachoma

\begin{tabular}{llllll}
\hline Pearson & 0.076325553 & -0.016955998 & $0.2032281^{* *}$ & $0.122185329^{*}$
\end{tabular}

correlation

$\begin{array}{lllll}\text { Sig. } & 0.080123721 & 0.377701099 & 8.06515 \mathrm{E}-05 & 0.012125241\end{array}$

(1-tailed)

\begin{tabular}{lllll}
$\mathrm{N}$ & 340 & 340 & 340 & 340 \\
\hline
\end{tabular}

**Correlation is significant at the 0.01 level (1-tailed); *Correlation is significant at the 0.05 level (1-tailed)

Table 6: Respondents WTP for environmental quality improvement

\begin{tabular}{lll}
\hline WTP & Yes & No \\
\hline Respondent & 317 & 23 \\
Ratio & $93.24 \%$ & $6.76 \%$ \\
\hline
\end{tabular}

Table 7: Respondents WTP level for environmental quality improvement

\begin{tabular}{lrrrrrc}
\hline WTP level & \multicolumn{1}{c}{0} & \multicolumn{1}{c}{1} & 2 & \multicolumn{1}{c}{3} & \multicolumn{1}{c}{4} & \multicolumn{1}{c}{5} \\
\hline Respondent & 31.00 & 22.00 & 68 & 108.00 & 48.00 & 63.00 \\
Ratio (\%) & 9.12 & 6.47 & 20 & 31.76 & 14.12 & 18.53 \\
\hline
\end{tabular}

government implements a program for improving environmental quality by choosing from either of the 6 levels of payments $(0,10.000,20.000,30.000,40.000,50.000$ VND). VND is an unit of Vietnamese currency. As shown in Table 6 and 7, 317 (93.24\%) respondents were willing to pay while only $23(6.76 \%)$ respondents were not willing to pay for improved environmental quality. This implies that the majority of the respondents were aware of the potential risks of environmental pollution and that they are willing to pay for improvements in environmental risk reduction programs.

Result of logistic regression analysis: In this study, binary regression model was used for analysis of WTP. After dropping variables that did not have statistical significance the remaining variables namely; WTP level, income, treatment cost, dermatitis, trachoma, respiratory, pneumonia, valuation of the extent of air pollution, gender, age, education and occupation were included as independent variables in the model. Researchers used SPSS version 16.0 to estimate the regression coefficients. The result of estimation is shown in Table 8 . The value of -2 Log-likelihood which is 24.88 indicates that the model is highly significant in capturing the relationship between
Table 8: Result of logistic regression model

\begin{tabular}{lrcccc}
\hline Variables & \multicolumn{1}{c}{$\mathrm{B}$} & \multicolumn{1}{c}{ SE } & Wald & df & Sig. \\
\hline Income & $1.8 \mathrm{E}-06$ & $8.81188 \mathrm{E}-07$ & 4.299022 & 1 & 0.038134 \\
WTP level & 0.00075 & 0.000263271 & 8.142156 & 1 & 0.004325 \\
Treatment cost & $-4.7 \mathrm{E}-06$ & $2.18753 \mathrm{E}-06$ & 4.560481 & 1 & 0.032718 \\
Gender & -4.29919 & 2.026484726 & 4.500763 & 1 & 0.033880 \\
Age & 0.25508 & 0.141777027 & 3.236976 & 1 & 0.071993 \\
Education & -2.98397 & 0.806509628 & 0.123581 & 1 & 0.725182 \\
Occupation & -2.98397 & 2.008541524 & 2.207129 & 1 & 0.137374 \\
Assessment of & -3.12040 & 1.732198883 & 3.245081 & 1 & 0.071638 \\
air pollution level & & & & & \\
Dermatitis & 6.25962 & 2.588975829 & 5.845747 & 1 & 0.015615 \\
Pneumonia & -4.21859 & 1.998986074 & 4.453635 & 1 & 0.034820 \\
Respiratory & 5.45789 & 2.266110024 & 5.800789 & 1 & 0.016019 \\
Trachoma & 0.06810 & 1.34012011 & 0.002582 & 1 & 0.959471 \\
Constant & -6.51299 & 4.822159885 & 1.82422 & 1 & 0.176812 \\
-2 Log likelihood & 24.88300 & CSR square & 0.34416 & NR & 0.881457 \\
& & & \multicolumn{3}{c}{ square } \\
\hline
\end{tabular}

the dependent variable and explanatory variables included in the model. Most of the variables included were found to be strongly correlated with the WTP variable (Table 8). The disease factors like dermatitis, trachoma, respiratory and pneumonia also significantly affect the probability of individuals WTP for environmental quality improvement. However, the respiratory problem has negative relationship with WTP, i.e., higher risk of perceived respiratory problems are associated with lower probability of WTP for environmental improvement. Along with the respiratory factor the cost of the treatment of typical diseases has also negative effect on WTP with correlative coefficient is -4.6 E-6 and is statistically significant. Besides the group of these disease factors and their cost of treatment, the individual socioeconomic factors were found to have their respective influences on the willingness to payment of the individual. Specifically, gender has a strong negative impact on the WTP. On the other hand, income and age were found to have positive impacts on WTP. Factors like the assessment of air pollution level, occupation and education did not have statistically significant impact on WTP.

Result of linear regression analysis: Linear regression model was used to analyze the impact of the core elements that influence WTP level. The explanatory variables included in the model were the individual socioeconomic characteristics the disease and treatment costs and the individual assessment of the extent of air pollution. The socio-economic variables included were income, gender, age, education and occupation. The variables on disease factors included in the model were some typical conventional diseases like pneumonia, respiratory problems, trachoma and dermatitis. Other variables included were individual valuations of air pollution state and treatment costs.

The results of linear regression analysis are shown in Table 9. The model was statistically significant and the 
Agric. J., 7 (5): 273-281, 2012

Table 9: Result of linear analysis

\begin{tabular}{|c|c|c|c|c|c|}
\hline \multirow[b]{2}{*}{ Variables } & \multicolumn{2}{|c|}{ Unst. coefficients } & \multirow[b]{2}{*}{$\begin{array}{l}\text { St. coefficients } \\
(\beta)\end{array}$} & \multirow[b]{2}{*}{$\mathrm{t}$} & \multirow[b]{2}{*}{ Sig. } \\
\hline & $\mathrm{B}$ & $\mathrm{SE}$ & & & \\
\hline Constant & -7929.09600 & 4493.294920 & - & -1.764650 & 0.0785530 \\
\hline Gender & 180.6217962 & 1449.425639 & 0.006150937 & 0.124616 & 0.9009040 \\
\hline Age & 358.0601190 & 105.3900016 & 0.170574031 & 3.397477 & 0.0007640 \\
\hline Education & 2439.522706 & 855.3061178 & 0.142194227 & 2.852222 & 0.0046170 \\
\hline Occupation & 7554.498486 & 2832.343432 & 0.126643839 & 2.667225 & 0.0080270 \\
\hline Airs & 63.90574858 & 1119.265294 & 0.002546126 & 0.057096 & 0.9545030 \\
\hline Dermatitis & -147.0452468 & 1465.833426 & -0.004963619 & -0.100320 & 0.9201550 \\
\hline Pneumonia & 886.2816346 & 1346.816332 & 0.030043351 & 0.658057 & 0.5109630 \\
\hline Respiratory & 3953.076920 & 1503.166407 & 0.130502334 & 2.629833 & 0.0089450 \\
\hline Trachoma & 1562.881675 & 1443.047775 & 0.052756202 & 1.083042 & 0.2795850 \\
\hline Income & 0.001081789 & 0.000136014 & 0.427034984 & 7.953501 & $2.97 \mathrm{E}-140$ \\
\hline Treatment cost & $5.51195 \mathrm{E}-05$ & 0.001833296 & 0.00142490 & 0.030066 & 0.9760330 \\
\hline $\mathrm{R}$ & - & 0.617203566 & $\mathrm{R}^{2}$ & - & 0.3809402 \\
\hline A. $R^{2}$ & - & 0.360179091 & $\mathrm{SE}$ & - & 11755.372 \\
\hline
\end{tabular}

Table 10: Estimation of WTP

\begin{tabular}{lc}
\hline Estimations & Currency unit (VND) \\
Mean WTP & 29088.23500 \\
Media WTP & 30000.00000 \\
Truncate WTP & 19749.76390 \\
WTP of trachoma & 17073.24593 \\
WTP of respiratory & 24247.85301 \\
WTP of pneumonia & 11367.27651 \\
WTP of dermatitis & 25315.08039 \\
Mean treatment cost & 29088.23529 \\
\hline
\end{tabular}

independent variables explain $61.72 \%$ of the variation in the dependent variable. Almost all of the individual characteristics were found to have positive impact on WTP level and were statistically significant with the exception of the gender variable. In particular, occupation in this study, researchers have classified occupation into 2 typical is who have income and who have not income that means who is getting support from family or other people. For example, student had the most powerful influence on willingness to pay for environmental quality improvement with an estimated coefficient of 7554.5 while income had the lowest effect with the regression coefficient of about 0.001 . The only disease found to have significant impact on WTP level was respiratory disease.

Estimation of the willingness to pay and cost for treatment: As described in this study, the impact of the treatment cost on WTP and WTP level is relatively strong on the WTP for environmental improvement and suit to the initial assumption (the disease and treatment cost have strong impact on WTP). As shown in Table 10, the mean treatment cost was 29088.23529 VND. The mean WTP was 29088.235 VND lower than the mean truncate WTP 19749.7639 VND. In this study, researchers estimated WTP for three kinds of the specific diseases. However, estimation for the combination of them was not carried out. The results show that WTP for dermatitis is highest with 25315.08039 VND followed by that for respiratory disease with $24247.85301 \mathrm{VND}$ and for pneumonia with 11367.27651 VND.

\section{CONCLUSION}

Issues of environmental quality have attracted a great deal of concern and interest on the part of environmental policy makers and researchers in recent years. This is primarily because of the far reaching consequences including health, resource degradation, ecological imbalance, climate change, natural disaster and economic damage. One of the most commonly considered problem is the determination of the economic benefit of environmental quality through estimation of WTP. This study, therefore investigated that the effect of conventional health problems related to environmental pollution and their treatment cost on individuals' Willingness To Pay (WTP) for common goods (the environmental goods) or non-market goods.

Accordingly, it was found that the impact of environmental pollution varied by the type of the health problem under consideration. More specifically, pneumonia had negative impact on WTP while respiratory problems and dermatitis had positive impact on WTP. The treatment cost also had a strong positive impact on the WTP level. The WTP level is estimated in this study to be 19749.7639 VND in truncate WTP. On the other hand, using contingent valuation method based on survey data gathered through questionnaire the study has assessed the extent of environmental pollution and identified the sources of environmental pollution.

Moreover, WTP estimating process and determining its affected factor on aspect of economics for the environmental quality improvement then environmental economists and policy makers should added more the factors of disease and their treatment cost as the crucial factors for study's target and policy analysis in assessing the environmental quality and setting up its improvement fund. In the case of Hanoi city, the policy makers should focus on designing policies that can reduce air pollution. They should give high priority on the need to solve the current problem by putting in place specific regulations and implementing them strictly to limit the release into the 
atmosphere of pollutants. Specifically, government should give due consideration to sources of pollution like transport and construction which were identified in this study as main sources in Hanoi, to maximally limit the released sources. The estimated amounts for implementing and charging the fund of environmental protection could range from 19749.7639-11367.27651 VND.

\section{REFERENCES}

Amirnejad, H., S. Khalilian, M.H. Assareh and M. Ahmadian, 2006. Estimating the existence value of North Forests of Iran by using a contingent valuation method. Ecol. Econ., 58: 665-675.

Arin, T. and R.A. Kramer, 2002. Divers'willingness to pay to visit marine sanctuaries an exploratory study. Ocean Coastal Manage., 45: 171-183.

Bowker, J.M. and J.R. Stoll, 1980. Use by dichotomous choice nonmarket methods to value the whooping crane resource. Am. J. Agric. Econ., 70: 372-381.

Haab, T.C. and K.E. McConnell, 2000. Valuing Environmental and Natural Resources: The Econometrics of Non-market Valuation. Edward Elgar, Cheltenham, UK.
Hanemann, W.M., 1984. Discrete/continuous model of consumer demand. Econ. Soc., 52: 541-561.

Lee, C.K. and S.Y. Han, 2002. Estimating the use preservation value of national parks tourism resource using a contingent valuation method. Tourism Manage., 23: 531-540.

Metchell, R.C. and R. Carson, 1980. Using Surveys to Value Public Goods: The Contingent Valuation Method. Resource for the Future, Washington, DC., Pages: 463.

World Bank, 2007. Cost of pollution in China: Economic estimates of physical damages. Brief Status Report, World Bank, Washington, DC USA., http://siteresources.worldbank.org/EXTUNITFESS D/Resources/1633787-1196098351543/CoPC_ presentation.pdf.

Zhongmin, X., C. Guodong, Z. Zhiqiang, S. Zhiyong and J. Loomis, 2003. Applying contingent valuation in China to measure the total economic value of restoring ecosystem services in Ejina region. Ecol. Econ. J., 44: 345-358. 